\title{
BMJ Open Patient and physiotherapist perceptions of rehabilitation following primary lumbar discectomy: a qualitative focus group study embedded within an external pilot and feasibility trial
}

To cite: Rushton $A$,

Heneghan NR, Heap A, et al. Patient and physiotherapist perceptions of rehabilitation following primary lumbar discectomy: a qualitative focus group study embedded within an external pilot and feasibility trial. BMJ Open 2017;7:e015878. doi:10.1136/ bmjopen-2017-015878

- Prepublication history and additional material are available. To view these files please visit the journal online (http://dx.doi.org/ 10.1136/ bmjopen-2017-015878)

Received 5 January 2017 Revised 10 March 2017 Accepted 23 March 2017

\section{CrossMark}

${ }^{1}$ Centre of Precision Rehabilitation for Spinal Pain (CPR Spine), School of Sport, Exercise and Rehabilitation Sciences, University of Birmingham, Birmingham, West Midlands, UK

${ }^{2}$ Physiotherapy, University Hospitals Birmingham NHS Foundation Trust, Birmingham, West Midlands, UK

${ }^{3}$ Institute of Applied Health Research, The University of Birmingham, Birmingham, UK

${ }^{4}$ Health Professions Department (Physiotherapy), Manchester

Metropolitan University,

Manchester, UK

Correspondence to

Dr Alison Rushton;

a.b.rushton@bham.ac.uk

\section{ABSTRACT}

Objective To evaluate patients' and physiotherapists' perceptions, preferences and feelings about rehabilitation following lumbar discectomy surgery.

Design A qualitative focus group study, informed from the theoretical perspective of phenomenology, of patients' and physiotherapists' experiences of rehabilitation following lumbar discectomy was conducted. The focus groups were used to explore patients' and physiotherapists' perceptions and their preferences and feelings about different approaches to rehabilitation. The focus groups were facilitated and observed by experienced researchers and were informed by a topic guide that had been piloted previously.

Setting The study was embedded within an external pilot and feasibility trial that randomised patients across two secondary care spinal surgery sites in the UK to receive either 1:1 physiotherapy and leaflet or leaflet-only interventions.

Participants Five focus groups took place between April and July 2014. A framework analysis of thematic coding (deductive and inductive components) by two researchers captured identified themes common to both patients and physiotherapists. Data from three focus groups with patients and carers $(n=11)$ and two with physiotherapists $(n=15)$ contributed to the analytic framework.

Results Emerging themes included: the value of patient leaflets with or without physiotherapy interventions; the importance of self-motivation in the recovery pathway; benefits of group physiotherapy for some patient groups and patient preference influencing rehabilitation.

Conclusion Patients and physiotherapists perceived the study patient leaflet and 1:1 physiotherapy interventions as high quality and valuable. Patients' personal priorities, for example, their need to return to work, influenced their preferences for rehabilitation interventions following surgery.

\section{INTRODUCTION}

The lifetime prevalence for low back problems is $80 \%$, representing a considerable health issue $^{1}$ with extensive financial (estimated
Strengths and limitations of this study

- This is the first study to inform understanding of rehabilitation following lumbar discectomy from both the patients' and physiotherapists' perspectives.

- The key strength of the study is that from the observer's perspective, the dynamics within the groups were all open and positive and this enabled participants to freely express their opinions.

- Positively, the groups appeared to have a facilitatory effect as individuals expressed opinions or experiences that then enabled others to relate to the issue and supported their contributions.

- This study was limited by its small sample, but it did satisfy our requirements for theoretical representativeness, that is, both male and female participants, all roles within the trial represented across both interventions.

- It is difficult to compare findings with the existing literature as minimal insights exist, and therefore transferability is limited.

$£ 10668$ million annually) and societal costs. ${ }^{2}$ Surgical management, including lumbar discectomy, is the largest single component of this expenditure. ${ }^{2}$ Lumbar discectomy is the excision of part of a prolapsed intervertebral disc in the lumbar spine for a primary indication of leg pain. ${ }^{3}$ Surgical success rates are estimated at $46-75 \%$ patients at $6-8$ weeks, and $78-95 \%$ patients $1-2$ years post-surgery. ${ }^{3}$ It is therefore an effective procedure for many patients. It is also a common procedure, with annual estimates of 12000 patients undergoing lumbar discectomy in the Netherlands, ${ }^{4} 287122$ in the $\mathrm{USA}^{5}$ and 8478 in the UK National Health Service. ${ }^{6}$

Following lumbar discectomy, there is significant variability in postoperative rehabilitation and advice offered by both surgeon ${ }^{7}$ and physiotherapist. $^{8}$ For example, the 
provision of outpatient physiotherapy is dependent on hospital and surgeon, and the content and number of sessions vary. ${ }^{8}$ In addition, systematic reviews report few trials of low risk of bias and no moderate or high quality evidence to inform postoperative rehabilitation. ${ }^{39}$ Some evidence suggested rehabilitation reduces disability, with a potential benefit of exercise and a more intensive intervention; and low quality evidence supports physiotherapy commencing at 4-6 weeks compared with no treatment or education alone. ${ }^{39}$ These data question optimal rehabilitation. The clinical evidence also suggests ongoing disability for some patients, with $30-70 \%$ patients experiencing residual pain. ${ }^{10}$ Reoperation is also an issue with $3-12 \%$ patients requiring further surgery in the Netherlands ${ }^{11}$ and $14 \%$ in the UK. ${ }^{6}$

Patient-reported outcome measures are now frequently used in trials as secondary outcome measures ${ }^{39}$ and capture the patient perspective of the impact of disc pathology and management on patient symptoms, function and quality of life. Beyond this, the focus within the literature is on clinical outcome data, for example, pain, disability and necessity for reoperation. Some prognostic studies also exist (eg, den Boer $e t a l^{2}$ ) that employ cut-off values for good or poor outcome, again usually based on clinical outcome data. Minimal qualitative research exists in this area to explore patient perceptions of surgery, rehabilitation or outcome. This is particularly important as the mean age of patients undergoing lumbar discectomy surgery is 45 years, ${ }^{3}$ a key working age, and represents multiple challenges for recovery and return to work. A qualitative case study in Canada ${ }^{13}$ interviewed 28 patients following lumbar discectomy performed on an outpatient basis. Overall, patients were satisfied with the amount and quality of information they received and found the experience positive. Important issues for patients were trust in the surgeon and significant back pain immediately postoperatively. Perceptions of rehabilitation were not investigated. Conversely, a UK study ${ }^{14}$ interviewed eight patients post lumbar discectomy to find out their experiences of rehabilitation. Patients described a transition from certainty to uncertainty relating to activity and a need for precise guidelines about movement limitations. They also reported activity potential was not explored and fatigue was not addressed.

Qualitative research is a rare occurrence in studies investigating surgical outcome, and yet it can afford valuable insight into the patient experience and outcome. Perceptions of patients are an important component of a practitioner's clinical reasoning. In addition, the perceptions of practitioners delivering rehabilitation are valuable and can inform the optimisation of interventions and, in turn, help improve the experience and outcomes for future patients. They can also importantly highlight differences in views between patients and physiotherapists. $^{15}$

The aim of this study therefore was to evaluate patients' and physiotherapists' perceptions (including their preferences and feelings) about rehabilitation following primary lumbar discectomy.

\section{METHODS}

\section{Theoretical framework}

The study was underpinned by phenomenology as it aimed to seek an in-depth understanding of reality from individual patient and physiotherapists' narratives related to their experience of rehabilitation following lumbar discectomy. The study is reported in line with the Consolidated Criteria for Reporting Qualitative Research (COREQ). ${ }^{16}$

\section{Design and setting}

A qualitative focus group study of patients' and physiotherapists' experiences of rehabilitation following lumbar discectomy was embedded within an external pilot and feasibility trial (ISRCTN registry 33808269). ${ }^{17}$ Within the trial, patients across two UK sites (Queen Elizabeth Hospital Birmingham (QEHB) and Salford Royal Foundation Trust (SRFT)) were randomised to either an optimised 1:1 physiotherapy intervention ${ }^{18}$ plus patient leaflet $(n=29)$ or patient leaflet ${ }^{19}$ alone $(n=30)$. The trial ran from January 2013 to July 2014, inclusive of recruitment, intervention, outcome assessment and focus groups.

\section{Focus groups}

Focus groups were used to maximise insight into patient and physiotherapist perceptions through the interactive group process. ${ }^{20}$ We were able to observe immediate reactions between participants as they either supported or challenged one another's views. ${ }^{21}$ We were able to evaluate knowledge, experiences and attitudes ${ }^{22}$ regarding the two interventions, including individual participant progress and ability to return to work/full function following their surgery, and the role of rehabilitation within the process.

\section{Focus group procedure and topic guide}

The focus groups were led by an experienced researcher/ facilitator (AR, chief investigator, physiotherapist, principal investigator QEHB trial site), who provided general introductory questions to encourage participant engagement, questions and prompts as required and ensured that all participants were able to contribute. The groups were observed by an experienced researcher (PCG, co-investigator, physiotherapist, principal investigator SRFT trial site) who ensured that all participants had the opportunity to express their views, recorded verbal and non-verbal group dynamics and a summary of the key emergent issues.

The topic guide (table 1) was informed by the literature and trial interventions and was piloted. Discussions lasted 90-120 min and continued until data saturation was felt to be complete. PCG was also responsible for an audio recording of groups, and a research assistant transcribed the audiotapes verbatim. Both AR and PCG are experienced musculoskeletal physiotherapists who have worked with lumbar discectomy patients for several years and had lead roles within the trial. This provided 
Table 1 Focus group topic guide

\begin{tabular}{|c|c|}
\hline Stage of focus group & Content \\
\hline Welcome & Participants welcomed to the focus groups with refreshments. \\
\hline Introduction & $\begin{array}{l}\text { Facilitator provided background to the group, clarity of its purpose, established the } \\
\text { agreement of ground rules for the group, answered any questions }\end{array}$ \\
\hline Consent & Written informed consent gained from participants willing to participate \\
\hline Audio recording & $\begin{array}{l}\text { Participants were familiarised with the audio recorder prior to the start of the } \\
\text { recording }\end{array}$ \\
\hline $\begin{array}{l}\text { Discussion of physiotherapy } 1: 1 \\
\text { intervention }\end{array}$ & $\begin{array}{l}\text { Broad questions: } \\
\text { What do you like about it? } \\
\text { Is there anything that you do not like about it? } \\
\text { Did you find it helpful? } \\
\text { Can it be improved? } \\
\text { Any other thoughts? } \\
\text { Prompts included: } \\
\text { Guiding principles } \\
\text { Detailed problems } \\
\text { Possible content of treatment } \\
\text { Personal experiences } \\
\text { Feelings related to the intervention } \\
\text { (details of physiotherapy intervention available for review) }\end{array}$ \\
\hline $\begin{array}{l}\text { Prompts for any further comments } \\
\text { regarding experience of rehabilitation }\end{array}$ & $\begin{array}{l}\text { Based on dialogue in group and notes from observer/facilitator } \\
\text { Personal experiences } \\
\text { Feelings related to the interventions }\end{array}$ \\
\hline Summary and close & Brief summary provided along with a final invitation for additional comments \\
\hline
\end{tabular}

the facilitator and observer with a strong background in the issues discussed, enabling effective follow-up of key points. ${ }^{23}$

\section{Participants}

Sampling and recruitment

All patients $(n=59)$ participating in the trial (eligibility criteria detailed in Rushton et $\mathrm{al}^{17}$ ) were invited, by telephone, to a focus group by the principal investigators (AR/PCG) at their respective trial site. All physiotherapists participating in the trial (SRFT $n=12 /$ QEHB $n=11$ ) were invited to participate by the clinical site lead physiotherapist. Five focus groups took place between April and July 2014. Patients from both arms of the trial were represented in each focus group. All trial physiotherapist roles of introducer, recruiter, assessor and treating physiotherapist, including both inpatient and outpatient physiotherapists, were represented. ${ }^{17}$

\section{Trial rehabilitation interventions}

The surgery-specific patient leaflet was developed through a Delphi process involving patients, physiotherapists and spinal surgeons. ${ }^{19}$ The 1:1 physiotherapy outpatient intervention encompassed education, advice, mobility exercises, core stability exercises, a progressive approach to exercise to increase intensity and encouragement of early return to work and activity. ${ }^{18}$

\section{Ethical approval}

The UK West Midlands Solihull Research Ethics Committee granted ethical approval (Ref:12/WM/0224). Research and Development approval was gained from 
both trial clinical sites. At the beginning of each focus group, the participant information sheet was discussed and any questions were answered. Anonymity, confidentiality and concept of voluntary participation were carefully explained. Participants provided written informed consent.

\section{Data analysis}

Data were analysed following guidance from Kitzinger ${ }^{22}$, using the Krueger ${ }^{24}$ and Ritchie and Spencer ${ }^{25}$ framework analyses. The process of data analysis began during data collection, through the facilitation of the focus group discussions, and recording of each group by the observer and their notes. This enabled familiarisation with the data. AR and PCG read each focus group transcript and field notes several times and independently constructed a preliminary framework of thematic coding, organised through the identification of themes and subthemes, and supporting quotations (Q denoting QEHB focus group as source and S denoting SRFT). Differences arising from this process were discussed at several stages to reach an agreed framework. Deviant cases were actively sought and explored throughout the process to modify emerging themes. ${ }^{26}$ Once a framework was developed, data were indexed and charted using a process of sorting and arranging quotations.

The initial framework was informed by the structure of the topic guide and analyses were deductive in nature. The final stage was characterised by mapping and interpretation of the data, exploring and explaining patterns of association. In the analysis of each focus group's dynamics, we reflected on the questions proposed by Stevens. ${ }^{27}$ These considered: adherence to key issues; exploration of disagreements; common experiences and dominant views. No new themes were identified at the end of each focus group, suggesting that data saturation
Table 3 Identified themes and subthemes from physiotherapists regarding their experiences of delivering the interventions

\begin{tabular}{ll}
\hline Theme & Subtheme \\
\hline $\begin{array}{l}\text { Leaflet as a valuable } \\
\text { intervention }\end{array}$ & $\begin{array}{l}\text { High quality of the leaflet } \\
\text { Valuable content of the } \\
\text { leaflet } \\
\text { Can improve leaflet } \\
\text { Useful format of leaflet }\end{array}$ \\
$\begin{array}{ll}\text { Perceived acceptability of } \\
\text { leaflet-only intervention }\end{array}$ & $\begin{array}{l}\text { Disagreement regarding } \\
\text { acceptability }\end{array}$ \\
$\begin{array}{l}\text { 1:1 physiotherapy intervention } \\
\text { as a valuable intervention }\end{array}$ & $\begin{array}{l}\text { Educational role } \\
\text { Managing patient }\end{array}$ \\
& $\begin{array}{l}\text { Managing psychosocial } \\
\text { issues }\end{array}$ \\
$\begin{array}{l}\text { Group physiotherapy } \\
\text { intervention is more effective } \\
\text { for some patients }\end{array}$ & \\
$\begin{array}{l}\text { Patient preference influencing } \\
\text { rehabilitation }\end{array}$ & \\
\hline
\end{tabular}

had been achieved. Data were triangulated across patient and physiotherapist focus groups to capture findings common to both users of rehabilitation and those professionals who deliver it.

\section{RESULTS}

Participants

Twenty-six participants took part in five focus groups. Participants in the two SRFT patient focus groups included two men and three women. Participants at

Table 2 Identified themes and subthemes from patients regarding their experiences of rehabilitation

\begin{tabular}{ll}
\hline Theme & Subtheme \\
\hline Leaflet as a valuable intervention & Clarity of information \\
& Recommendations for further improvement \\
& Using it with others \\
& Alternative possible formats of leaflet intervention \\
Patient acceptability of leaflet-only & The leaflet providing confidence \\
intervention & Positive experiences following the guidance (exercises and timescales) in the \\
& $\begin{array}{l}\text { leaflet } \\
\text { Patients being realistic about guidance (exercises and timescales) }\end{array}$ \\
& Patient unacceptability of leaflet-only intervention \\
\hline Leaflet and 1:1 physiotherapy as a valuable & Physiotherapy providing confidence \\
intervention & Value of physiotherapy input \\
& $\begin{array}{l}\text { The need for written and face-to-face intervention } \\
\text { Some patients didn't mind travelling for treatment at hospital } \\
\text { Intrinsic motivation }\end{array}$ \\
\hline
\end{tabular}

Recommendations for further improvement

Using it with others

The leaflet providing confidence

Positive experiences following the guidance (exercises and timescales) in the Patients being realistic about guidance (exercises and timescales)

Patient unacceptability of leaflet-only intervention

Value of physiotherapy input

The need for written and face-to-face intervention

Some patients preferred to manage own recovery with leaflet to avoid trave

Differences between patients regarding their intrinsic motivation 
QEHB included three men and three women. Participants were representative of those who participated in the trial, and participants they represented both arms of the trial. One participant brought her partner (carer). The main reason for participants from the trial being unable to attend the focus groups was being back at work or difficult to travel (as both sites were regional spinal surgery centres and patients could live a considerable distance away). All participants in the physiotherapist focus group at SRFT were women $(n=7)$, whereas participants in the physiotherapist focus group at QEHB were men and women $(n=8)$. No participant having agreed to attend refused to participate/dropped out. The observer of the focus groups perceived that the dynamics were all open and positive, enabling all participants to contribute.

\section{Patient and physiotherapist perspectives}

Tables 2 and 3 detail the themes and subthemes derived from the patient and physiotherapist data, respectively. Emerging themes included: the value of patient leaflets with or without physiotherapy interventions; the importance of self-motivation in the recovery pathway; benefits of group physiotherapy for some patient groups and patient preference influencing rehabilitation.

Quotes supporting themes and subthemes from patients and physiotherapists regarding their experiences of rehabilitation are detailed in boxes 1 and 2, respectively.

\section{DISCUSSION}

\section{Key findings}

No focus groups have previously explored patient and physiotherapist perceptions of different approaches to rehabilitation following lumbar discectomy. Triangulation of data across the two groups of participants illustrated common findings for both users and providers of rehabilitation. Patients and physiotherapists perceived the patient leaflet and the 1:1 physiotherapy acceptable. Both thought the patient leaflet was comprehensive and clearly written, and for some, able to replace 1:1 care. They perceived it to provide information at the correct level and an essential part of postoperative care. One patient took it to the gym to use as a reference guide as they exercised. Despite the acceptability, there were useful recommendations for improvement, for example, extra exercises and information on pacing.

There were, however, some differences. Patients and physiotherapists disagreed about the acceptability of a leaflet-only intervention. Some patients were happy to continue their rehabilitation alone, but others felt they needed help from a physiotherapist to guide them. Patients welcomed the option to telephone a physiotherapist if they were concerned about progress. For others, the need to attend an appointment helped them continue their rehabilitation. Some physiotherapists found a leaflet-only intervention acceptable for some patients. However, other physiotherapists viewed their input as necessary to help patients take on-board instructions, to provide an 'emotional crutch' and manage expectations, and therefore perceived a leaflet-only intervention as unacceptable. In line with this perception, some patients expressed a need for face-to-face intervention. A number of physiotherapists suggested group intervention would be more effective for some patients, although this would not be feasible in all hospitals.

A prominent theme was the need to manage patient expectations. A large part of the physiotherapists' role was not hands on treatment, but advising; helping patients understand postoperative symptoms (eg, leg pain), milestones or the expectation of being seen a certain number of times. Physiotherapists described this function as providing a 'support system' and this role is supported by the literature. ${ }^{14}$ Patients with positive expectations around return to work, pain and disability tend to have greater satisfaction post-surgery, ${ }^{28}$ and multiple demographic, psychological and clinical characteristics affect patients' expectations. ${ }^{29}$

Physiotherapists acknowledged that patients did not always want to attend physiotherapy. One commented, "we ....expect people to want physio but it surprised me probably that it's not always the case". Although it is natural to expect patients want help, not all do. Even for those who do, we found variation between patients in their motivation towards getting better. Some illustrated a strong intrinsic motivation, sometimes from external factors such as their job or partner. Others lacked motivation because of low expectations, whereas others found it difficult to access transport or social or employer support to free up time to get to hospital for treatment.

There is a need for patient involvement to guide rehabilitation. Evidence shows that nearly half of patients prefer to be well informed about their disease and have an active involvement or a collaborative role in decision making that matches their preferences for participation before their lumbar discectomy surgery. ${ }^{30}$ Conversely, healthcare professionals also need to be aware that not all individuals prefer involvement in their rehabilitation decisions. ${ }^{30}$

The acceptability of the leaflet and 1:1 physiotherapy by patients and physiotherapists as valuable interventions provides evidence and support for their use. Some physiotherapists identified patients who would be suitable for group therapy once they had reached a certain level of function. There was an opinion that some patients would benefit from supervised exercise therapy and that a group environment was a safe, effective and cheaper way to achieve this. However, there are differing criteria for admission to classes, and for some hospitals, surgery in the previous 3 months is a contraindication to classes.

Clear from this study is the need to take into consideration patient preferences alongside clinical reasoning. Some patients require/prefer a leaflet-only intervention, while others require/prefer face-to-face contact and others may require/prefer attendance in a group environment. With this in mind, an option available to the healthcare provider is a choice of rehabilitation or stepped care approach to 
Box 1 Direct quotations supporting themes and subthemes from patients regarding their experiences of rehabilitation ( $Q$ denoting QEHB focus group as source and S denoting SRFT)

Patients found the patient leaflet a valuable intervention. In particular, they liked the clarity of information presented, particularly in terms of language used and simple explanations.

"I'm glad it's just in plain English, you've got no medical jargon in and that's a bonus I think". (S)

"It's good to have something that says - this is what you do in basic English. It's easy enough to understand and easy enough to follow". (S)

Patients found the level of the leaflet appropriate without being patronising.

'Clearly set out, it is not written in a way that I think I don't understand that wording". (S)

"It's pitched at the right sort of level". (S)

"It's not patronising; you need to know it". (S)

They found the leaflet detailed enough to know what they needed to do following the initial overview of the leaflet provided by the physiotherapist. The surgery-specific nature of the leaflet was seen as positive.

"It explains to a degree that you can understand what's wrong with my back, that's where they have shown me this is wrong, and this is pressing on this. You know, it gives you an understanding of it and why you're then having to do particular exercises or why they have to do particular types of operation of you". (S)

"I didn't need any pointers to do my exercises, you couldn't get it wrong". (Q)

Some patients made suggestions for how the leaflet may be improved further.

"If there would have been a list in the back of how many times you should do it, I would have recorded them, because that's just me and I'm on track then". (S)

'It doesn't tell you what things you can't do. For example going to the gym and doing bicep curls, and doesn't say how much pressure it puts on the back. It does tell you certain exercises you can do, but doesn't tell you what could cause you a problem". (Q)

"It just gives you a guideline on what to expect at week 1, week 3, week 6 but that again is a bit broad. So something that was a bit more focused on the individual and what to expect would help expectations". (S)

'I think now looking back, if there was a bit in there saying 'yeah you could start feeling down', that would be useful for anybody else who has it because I just thought it was me being mad. Because I wasn't doing what I thought I should be doing, at this stage". (S)

Some patients found the leaflet valuable to involve others, for example, their partners, within their rehabilitation.

"I think the leaflet again is useful to the partners to get through". (Q)

"I would take it [the leaflet] to the gym with me and show everyone and they would help". (Q)

Some patients discussed alternative or additional formats for the patient leaflet. A couple of patients felt that a CD would be useful.

"Having a CD with one of you physio-terrorists showing how the exercises should be done". (Q)

"You can see it being done properly". (Q)

Patients were not keen on the idea of using an App.

I would use it, but I would still prefer to see a physiotherapist. (Q)

"I think the older generation wouldn't [use an App]". (Q)

Patients welcomed the option of being able to telephone the department to speak to a physiotherapist if they were concerned about their progress.

"I ended up ringing back, ...... that was the people on the ward and they said in the first week, if anything doesn't feel right, ring us because

sometimes it might be something or nothing which mine was. They said not to worry, you've done the right thing but if it was something that was more serious, they would ask you to come back and sort it out. You know it is helpful knowing you've got the number and that you can ring them". (S)

Patients disagreed regarding the value of telephone or Skype contact with the physiotherapist instead of face-to-face contact.

Yeah, definitely. If I'd have known somebody [would] ring me......... Yeah, and I would ask all these questions I'm asking you".(S)

"Sorry, I think I'm old fashioned - face to face, face to face. Telephone fine, but not only telephone. I would have like something visual because I'm that sort of person". (S) "Although I use a computer, I don't use skype but it's sitting in front of a computer and in those first 4 or 5 weeks, you wouldn't be able to". (S)

"I mean if that would have been an option I would have taken it. I could skype with my phone but I don't, that would encourage me to". (S)

"You wouldn't be able to do it whilst you were at work would you. If you were having a problem with recovery for whatever reason, yeah it might be a good idea, but I think if you were okay and you'd gone back to work, then no, I don't see the point”. (S)

"It [skype] couldn't be a replacement but I think in certain circumstances, for certain people and certain visits - yes, absolutely. I mean I often been to a physio and we've just talked, you know I could have talked in my front room". (S)

"The fact I had to go made me do it; I'd have got so lazy if I thought somebody was going to phone me up or come round. So for me, I had to get up and do it, so it wouldn't have worked for me, otherwise I would have just sat there". (S)

Patient acceptability of leaflet only intervention theme

Some patients were very happy and wanted the patient leaflet intervention, rather than attending for physiotherapy. Patients described the leaflet as providing confidence.

"I used it to refer back to. l'd look at the instructions again and think 'yeah l'm okay". (Q)

"I could feel symptoms changing as time went on and we progressed". (S)

"There were certain ones I remember I couldn't do. I think there was one that we said to miss out, I think it was the bridging, but it was very, very

helpful. I was relating to it every day, making sure I was doing them correctly". (S)

The patients described positive experiences following the guidance (exercises and timescales) in the leaflet.

"I think they were good, but it's individual at the end of the day. Some might be quicker, some might take longer". (Q)

Continued 


\section{Box 1 Continued}

"I had got quite a lot of movement back doing the stages as recommended in the leaflet, and when I last saw the physiotherapist here, she was amazed at the amount of flexion that I had been able to regain. And I think that was really interesting as I was sticking to the exercises in the book". (Q) "Not everything I wouldn't say fitted in, but I just sort of followed it and it was fine for me". (S)

"Once you've started to get mobile, it's easier each time you do them". (Q)

Patients also demonstrated a realistic approach to the guidance provided (exercises and timescales), although some (although understanding that rates of progress can vary) voiced feeling disheartened if they were not complying with the suggested milestones.

"It sort of gave you an idea of what to expect, I mean sometimes you did get to a point where you were thinking, okay l'm at 5 weeks now and I'm still in $0-4$, is there something wrong?" (S)

"Well again it's kind of like a standard benchmark, after 4 weeks you'll be able to this and so on, but everyone's different". (S)

"Except for the timescale indications, that can be very disheartening to be told that you should be doing it in 4 weeks when you're not" (S)

"Yes, you're thinking you've got into week 5...... Anyway I went on, took less and less painkillers, and you're thinking it is getting better now because I know l've not got to take 4 lots of this, that and the other". (S)

"The other stuff I read lead me to believe that everyone is very individual so I just had less and less confidence in the milestones". (S)

However, some patients felt that they needed more than the patient leaflet to guide their rehabilitation.

"I felt lonely doing this, and because I wasn't doing my social things, and I had no need to push myself because I was no way near as fit as them". (S) "I have slipped back and I found it a struggle to do this, I really did. I did them, but some of them caused me pain, so I went back to my physio, because I thought, I've got to get sorted what I am doing, and his number one thing was slow down and don't do the things which cause you pain". (S) "I know what my goals are, but how fast I should there, is something I can't judge for myself and I'm slightly worried ...." (S)

"Sometimes you did get to a point where you were thinking, okay l'm at 5 weeks now and I'm still in 0-4, is there something wrong? Because shortly after I got home, I did ring them and ask questions...." (S)

"A physio would have been very helpful to say 'right start doing that again, now' and l've just not had that and l'm looking for ways to get it to improve this summer. ...... And I do feel I would have been here, with the physio..." (S)

"... when I went and took this leaflet along to my physio, he said great, but terrible, you're doing it far too aggressively". (S)

"...I need the constant reassurance". (S)

\section{Leaflet and 1:1 physiotherapy as a valuable intervention theme}

Patients perceived the 1:1 physiotherapy as providing confidence.

"Because it does actually build your confidence up because if there's someone there showing you and explain to you that you can actually go along with confidence". (Q)

"I was more confident at work". (Q)

"I couldn't possibly have done it without the physiotherapist to get to this level of recovery". (S)

Patients valued the input from the physiotherapist.

I would still prefer to see a physiotherapist and you know, you can talk to them then too". (Q)

"I don't think you can avoid thinking 'are you doing it 100\% accurate?'There were a few exercises where I wondered whether I was doing them right and obviously if you went to a physio, they could show you and correct you if needed". (Q)

"A physio would have been very helpful to say 'right start doing that again, now." (S)

"Because l've got nobody else to ask and after several weeks of this pain, I thought well l'll get some advice and go back to the physio". (S)

Some patients particularly felt they needed both the written leaflet and the physiotherapist face-to-face components.

"For me I thought both leaflet and physio were essential". (Q)

"The leaflet was something I would do in the morning, and then I came here [Hospital] as well". (Q)

"I know what my goals are, but how fast I should there, is something I can't judge for myself". (S)

"The physio could tell you what you were doing right or wrong. It was ideal for me". (Q)

Patients disagreed regarding the need to travel for treatment at the hospital. For some, the travel was a considerable distance but worth it. For others, they preferred to manage their own rehabilitation to avoid the travel.

"Surely if you're health is more important, that travelling for so many minutes wouldn't be a problem if it was getting me right". (Q)

"Yeah it wasn't a problem for me as we're both retired". (Q)

"The fact that I had to get up and go out and do it - if I'd have known someone was coming to the house I think I'd have just sunk further into feeling depressed knowing that I didn't have to get up and do it". (S)

"If I can do it at home, and that's what you're supposed to be doing, it's easier to do that and be in your own surroundings rather than travel 8 or 9 miles to an hospital and then be in pain because of the travel and then be in more pain when they've bent you in different places and you've got to survive a journey back home and you think, well that was pointless - I'm in more agony now than what I was before, you know, I could have done a walk round the block a few times or something". (S)

"I don't know if most of us are local people but I've had a 50 minute journey here this morning, which if l'd have had to have come in the department regularly, then that's a big chunk out of our daily living which we would have been able to fulfil by the use of the leaflet". (Q)

"My husband's prepared to not book appointments to his work so that he can bring me. If my husband didn't block off the day, then as I say, I would be stuck". (Q)

\section{Intrinsic motivation theme}

There was variation between patients in their motivation towards getting better. Some patients illustrated a strong intrinsic motivation, sometimes motivated by external factors, for example, their job. 


\section{Box 1 Continued}

And I think it's your determination to get well again". (Q)

"I've got to keep my job otherwise you can't afford to pay bills, and all the rest of it. You can't just sit and do nothing, you've gone down the root of: I'm in pain, I can't work because l'm in pain, because it was impossible as a sitting down job, and you just couldn't go in work and sit down for more than 5 minutes as you'd just be in agony....... So I tried to do everything I could, and thought this is going to hurt but I've got to do it, I've got to get myself back to be able to go back to work or you end up on no pay at all". (S)

"I did stick to my exercises". (S)

"I know that I have to because I know that my muscle won't work if I don't do them, so I have stuck to them. I wouldn't say I do every single one of them, but the ones that have been shown, I do use some of them, every single day". (S)

"I try and go (swimming) 4 times a week". (S)

However, others illustrated that motivation was an issue for them.

I can't motivate myself to do this, when it's not going to get me back to the extent I used to be". (S)

"I find it difficult to drive myself". (S)

"You can't tell someone you have to do this as your goal, it's up to you to choose what that is, because it could be something smaller". (S)

rehabilitation. Stepped care has been discussed for back pain $^{3132}$ and non-back-related conditions, ${ }^{33-36}$ and is recommended by the National Institute for Health and Care Excellence (NICE) for conditions including mental health disorders. ${ }^{37}$ A stepped care approach takes into account patient preference in the rehabilitation they receive in conjunction with a physiotherapist's clinical reasoning. While the stepped care is evidence based, patients advance through the steps as far as they want and/or need to. They start with the least intensive step 1 (eg, leaflet), if necessary progress onto a more intensive step 2 (eg, 1:1 physiotherapy) and finally step 3 (eg, group intervention). To our knowledge, this approach has not been evaluated for patients post lumbar discectomy. There is therefore a need to evaluate the effectiveness/cost-effectiveness of such an approach.

Qualitative studies until now have explored perceptions of outpatient surgery, ${ }^{13}$ so are not directly comparable, or only considered the patient perspective. ${ }^{14}$ Previous studies have reported general patient satisfaction with the care they receive pre ${ }^{28}$ and post $^{8}$ lumbar discectomy surgery. However, historically, they have been less satisfied with the verbal $^{28}$ and verbal/written patient information provided ${ }^{8}$ that is commonly not surgery specific.

\section{Strengths and limitations}

The key strength of the study is that the dynamics within the groups were all open and positive and this enabled participants to freely express their opinions. ${ }^{22}$ The groups appeared to have a facilitatory effect as individuals expressed opinions or experiences that then enabled others to relate to the issue and supported their contributions. We observed no examples of participants being uncomfortable within a group and no participant having difficulty expressing their opinion/ experience. This study was limited by its small sample, but it did satisfy our requirements for theoretical representativeness, that is, both male and female participants, all trial roles for the physiotherapists and patients allocated to both interventions. It is difficult to compare findings with the existing literature $^{1314}$ as minimal insights exist, and therefore transferability is limited. The focus groups have, however, informed our understanding of rehabilitation from both the patients' and physiotherapists' perspectives.

\section{CONCLUSIONS}

From patient and physiotherapist focus groups post lumbar discectomy surgery, patient leaflet and 1:1 physiotherapy interventions were perceived as acceptable. Both patients and physiotherapists agreed that a patient leaflet-only intervention was acceptable for some, but that others required a 1:1 intervention, and for some, a group approach was indicated. Patient priorities are important as they do not always match those of the physiotherapist. To satisfy the needs of patients post lumbar discectomy, a stepped care approach might be valuable.

Acknowledgements The participants in the study for sharing their experiences and views. Claire Littleford and Christopher Bayliss, patient users, who supported trial management and trial steering groups that provided an overview of the focus groups.

Contributors Conceived and designed the study: ABR, MC, AH, LW and PCG. Performed the focus groups: ABR and PCG. Analysed the data: ABR and PCG. Overview of analysis and interpretation: ABR, NH, MC, AH, LW and PCG. Wrote the first draft of the paper: $A B R$ and PCG. Contributed to review and subsequent drafts of paper: ABR, NH, MC, AH, LW and PCG.

Funding This work was funded by the Queen Elizabeth Hospital Charity, Grant number 17-3-780. Authors receiving funding: AH, ABR, MC, LW and PCG. The funder had no role in study design, data collection and analysis, decision to publish or preparation of the manuscript.

Competing interests None declared.

Ethics approval The UK West Midlands Solihull research ethics committee granted ethical approval (Ref:12/WM/0224).

Provenance and peer review Not commissioned; externally peer reviewed.

Data sharing statement No further unpublished data are available.

Open Access This is an Open Access article distributed in accordance with the Creative Commons Attribution Non Commercial (CC BY-NC 4.0) license, which permits others to distribute, remix, adapt, build upon this work non-commercially, and license their derivative works on different terms, provided the original work is properly cited and the use is non-commercial. See: http://creativecommons.org/ licenses/by-nc/4.0/

(c) Article author(s) (or their employer(s) unless otherwise stated in the text of the article) 2017. All rights reserved. No commercial use is permitted unless otherwise expressly granted. 
Box 2 Direct quotations representing identified themes and subthemes from physiotherapists regarding their experiences of delivering the interventions

\section{Leaflet as a valuable intervention theme}

Physiotherapists described the leaflet as high quality.

"I get less calls from patients who had this leaflet than the ones who used the previous leaflet'." (Q)

"We still use it now." (Q)

"I was an assessor...... patients sometimes talk to me about the leaflets and they found it really useful and informative." (S)

"If there's more junior staff in our department, they might not know some of the answers to these frequently asked questions so it's quite a good tool for rotating members of staff as well." (S)

They found the content of the leaflet useful.

"I thought the FAQ section was really useful, as that covered a lot of things we were sort of asked anyway on the ward, and not necessarily covered or would tell them before unless they asked so it was quite nice to have those points in there. And the patients did seem to find that quite useful." (S)

"... and was very understandable and even the timings of things, like 4 weeks after surgery were very clear for patients to relate to and have as a guide." (S)

"And the other bit was even at the beginning when you've got about what happens during the surgery, that was quite useful because a lot of our patients didn't actually really know what they had had done." (S)

"...I like how the exercises are in the booklet, as it's nice to have everything in one place because outside of this study, what we would do is give them a booklet and an exercise sheet separately." (S)

Some physiotherapists felt that the leaflet could be improved further.

"I think the ankle movements one (exercise), I know why they're there but they're often up and about. I probably didn't use that one to be honest and was the one that I omitted the most because they were up and walking, so I didn't think it was that relevant for them." (S)

"Pelvic tilting is one (exercise) that other hospitals normally put in, which is sometimes easier for them to get than just doing trans abs." (S)

"You know the diagram you use sometimes, I use it for pacing, I don't know if that would be useful as I know that's something they struggled with was pacing." (S)

"You have a small percentage of people who are happy to go and find it online, I don't think we were going to replace the paper copies just yet, simply because of the ageing population we're dealing with. I think that's an area for development. You can get an app for Argos or Aldi now so after the operation it all makes sense doesn't it." $(Q)$

They liked the useful format of leaflet.

"I think the size is good. You know, if it was $8 \times 4$, is won't fit in your bag." (S)

"It's nice, it doesn't look too full, or look too intense to read. It does look nice and simple." (S)

"It is more detailed as well but like we said, if it's instead of seeing us it needs to be." (Q)

"I liked that you could tick the relevant ones (exercises)." (S)

\section{Perceived acceptability of leaflet-only intervention for patients' theme}

Physiotherapists disagreed regarding their perceptions of the acceptability of the leaflet-only intervention for patients. Some found it acceptable. "... at the end of the 26 week assessments, patients sometimes talk to me about the leaflets and they found it really useful and informative." (S)

"There would be some times where you were explaining things to a patient and they would say they'd already read it." (Q)

However, some physiotherapists did perceive the leaflet-only intervention as unacceptable.

"Something I found occasionally difficult is getting the feeling that this person needs to be seen 1:1 and you just wonder really, but you sort of follow the process but I just thought with some people, they're never going to take this on board themselves." $(Q)$

"I think what helps with having physio as well is that it's a bit of an emotional crutch as they have a fear of something going wrong and it's that, what if it gets worse and knowing they'll be seen and under the care of a physio, carries a lot of weight for a lot of people." (Q)

"I was a treater, and a lot of these things that are in this (leaflet) funnily enough were often asked to me as a treater. So, I don't know whether they read it and it didn't go in, or it needed to be reinforced Maybe that highlights that it is important that they are seeing physio then." (S)

"It's just that I would want to be giving somebody enough information to see them through their recovery if they weren't coming on to the treatment programme So yes, if they were coming on to treatment it might seem a bit wordy as there are things you could explain more quickly one to one, but this could be the patient's only intervention, so you need to explain more and in some, you need to explain less." (Q)

1:1 physiotherapy intervention as a valuable intervention theme

The physiotherapists perceived their role as valuable and as carrying out key functions, for example, an educational role.

"A lot of their treatment was based on education rather than physical treatment." (S)

"... it was a lot more about education than anything else." (S)

"I was shocked as to how much information they wanted rather than physical treatment." (S)

"... if you work in outpatients all the time, you want to get your hands on to somebody and sometimes you don't feel like you are treating them if all you're doing is talking to them; and maybe that was my problem rather than their problem. But that is treatment for them, that's what they wanted." (S)

"It was funny that week to week, we did the same thing and thought about the same things. And common themes were: not taking their painkillers right, and pacing." (S)

Physiotherapists also perceived that they had an important role managing patient expectations.

"A lot of them couldn't understand why their leg pain wasn't completely gone instantly." (S)

"They are always told about expectations of leg pain but it's how much they hear." (S) 


\section{Box 2 Continued}

"... when we talk about expectations is that it's almost as if they expected to be $100 \%$ better before they were discharged from physio. And that's dangerous, because it's hard then to discharge them." (S)

Also managing psychosocial issues.

"It was treatment of yellow flags, and pacing and how to take your pain relief, return to work." (S)

“... it was more like a support system." (S)

"As a whole the treaters perceive these patients to be a difficult patient." (S)

"I think they are a very anxious group of patients." (S)

"It was a lot of calming them down." (S)

Perception that group physiotherapy intervention is more effective for some patients' theme

Some physiotherapists would have liked to refer patients into group classes as part of their rehabilitation, feeling this would be more effective.

"The only other big thing is that we didn't put them in classes did we, and I don't know if that would have made a difference Here we're comparing

a 1:1 intervention versus a booklet, where as in normal environment, a class is the most efficient way to treat them and it does have that impact as

well." (Q)

"We tend to see them, assess them, get them to a certain level, tell them to go work on this, whether that includes a class or independently and thentell them to come back and review them again and then depending on their goals, you may want to progress them from there. It's obviously more efficient for the Trust to have everyone in a class than to see a Senior Physiotherapist." (Q)

"I definitely thought the group would have been the best place for most of them. Because then, they would have got the exercise element of it, and the education element of it. I don't know if you'd put them straight in, would that have been a bit of a disaster? Maybe one or two sessions on your own to answer their own personal questions, and then into the group." (S)

"I couldn't say they all needed the group, but the majority." (S)

However, physiotherapist did not agree on this issue, as several felt that a group class would not work for this population.

"I think that would be an exceptionally difficult group to run. I think a lot of them would have been really appropriate for our back to fitness group. We couldn't put them into the group, but I felt like seeing them one to one, if they would have just come to that group, it would have answered a lot of the questions they had, but we couldn't put them into that group." (Q)

"In real life, that's what a lot of them would have needed, a back to fitness, like other people with back pain. But it's a contraindication to our back group - surgery in the last 3 months or so. I think a lot of them would have been really appropriate for our back to fitness group." (S)

\section{Patient preference influencing rehabilitation theme}

Physiotherapist recognised that some patients had distinct preferences regarding their treatment.

"I think some people have an expectation of being seen $\mathrm{X}$ number of times on a weekly basis, that is normal for physiotherapy, so to try and explain otherwise and the number of hospitals up and down the country, they all follow that route. You just have to explain it clearly and for some people it's a bonus, they have good background knowledge, a busy life, it fits in better with their life but for some, it's a difficult pill to swallow and often in some cases on the basis that they might not receive one to one physio." (Q)

"That worked the other way as well as quite a few times we came down and there were quite a few people who didn't want the physio, they just wanted the leaflet but they were pulled out, so it works both ways. So I think we sort of expect people to want physio but it surprised me probably that it's not always the case." (Q)

\section{REFERENCES}

1. The burden of musculoskeletal conditions at the start of the new millennium.Geneva:World Health Organisation,2003.

2. Maniadakis N, Gray A. The economic burden of back pain in the UK. Pain 2000;84:95-103.

3. Oosterhuis T, Costa LO, Maher CG, et al. Rehabilitation after lumbar disc surgery. Cochrane Database Syst Rev 2014:CD003007. Art. No: CD003007.

4. van Bleek E, Lemmens K, van Schooten G, et al. Reduceren van Praktijkvariatie: budgettaire effecten van scherpere indicatiestelling. Breukelen: Plexus, 2010.

5. Sherman J, Cauthen J, Schoenberg D, et al. Economic impact of improving outcomes of lumbar discectomy. Spine J 2010;10:108-16.

6. All procedures and interventions 2013/14. 3 character. All procedures (V33) www.hscic.gov.uk/hes (Accessed 3 Mar 2016).

7. McGregor AH, Dicken B, Jamrozik K. National audit of postoperative management in spinal surgery. BMC Musculoskelet Disord 2006;7:47.

8. Williamson E, White L, Rushton A. A survey of post-operative management for patients following first time lumbar discectomy. Eur Spine J 2007;16:795-802.

9. Rushton A, Wright C, Goodwin P, et al. Physiotherapy rehabilitation post first lumbar discectomy: a systematic review and meta-analysis of randomized controlled trials. Spine 2011;36:E961-E97.

10. Ostelo RW, Goossens ME, de Vet HC, et al. Economic evaluation of a behavioral-graded activity program compared to physical therapy for patients following lumbar disc surgery. Spine 2004;29:615-22.

11. The lumbosacral radicular syndrome. Dutch Institute for Healthcare Improvement. Centraal Begeleidings Orgaan Report 2008.
12. den Boer JJ, Oostendorp RA, Beems T, et al. A systematic review of bio-psychosocial risk factors for an unfavourable outcome after lumbar disc surgery. Eur Spine J 2006;15:527-36.

13. Hersht M, Massicotte EM, Bernstein M. Patient satisfaction with outpatient lumbar microsurgical discectomy: a qualitative study. Can J Surg 2007;50:445.

14. Williamson J, Bulley C, Coutts F. What do patients feel they can do following lumbar microdiscectomy? A qualitative study. Disabil Rehabil 2008;30:1367-73.

15. Louw A, Louw Q, Crous L. Preoperative education for lumbar surgery for radiculopathy. S Afr J Physiother 2009;65:3-8.

16. Tong A, Sainsbury P, Craig J. Consolidated criteria for reporting qualitative research (COREQ): a 32-item checklist for interviews and focus groups. Int J Qual Health Care 2007;19:349-57.

17. Rushton A, Heneghan N, Heap A, et al. Physiotherapy Post Lumbar Discectomy: pilot and feasibility study to inform the development of a Randomised Controlled Trial. PlosOne 2015;10:22.

18. Rushton A, White L, Heap A, et al. Development of $1: 1$ physiotherapy intervention post first-time lumbar discectomy. BMJ Open 2016;6:e009409.

19. Goodwin PC, Wright CC, Allan C, et al. Evidence-based development of a post-surgical lumbar discectomy leaflet intervention: a Delphi consensus study. BMJ Open 2015;5:e006069.

20. Madriz E. Focus groups in feminist research. Handbook of qualitative research 2000;2:835-50.

21. Kidd PS, Parshall MB. Getting the focus and the group: enhancing analytical rigor in focus group research. Qual Health Res 2000;10:293-308. 
22. Kitzinger J. Qualitative research. introducing focus groups. BMJ 1995;311:299-302.

23. Kreuger A, Casey M. Focus groups: a practical guide for applied research. $3^{\text {rd }}$ ed. London: Sage Publications, 2000.

24. Krueger RA. Analyzing and reporting focus group results. Vol 6. London: Sage publications 1997.

25. Ritchie J, Spencer L. Qualitative data analysis for applied policy research. in: bryman $A$ and Burgess $R G$ (eds) Analyzing qualitative data. Abingdon: Routledge, 1994:173-94.

26. Pope $\mathrm{C}$, Ziebland $\mathrm{S}$, Mays $\mathrm{N}$, et al. Analysing qualitative data. BMJ 2000;320:114-6.

27. Stevens PE. Focus groups. Public Health Nurs 1996;13:170-6.

28. Rönnberg K, Lind B, Zoëga $B$, et al. Patients' satisfaction with provided care/information and expectations on clinical outcome after lumbar disc herniation surgery. Spine 2007;32:256-61.

29. Mancuso CA, Duculan R, Stal M, et al. Patients' expectations of lumbar spine surgery. Eur Spine J 2015;24:2362-9.

30. Rätsep T, Abel A, Linnamägi Ü. Patient involvement in surgical treatment decisions and satisfaction with the treatment results after lumbar intervertebral discectomy. Eur Spine $J$ 2014;23:873-81.
31. Von Korff M, Moore JC. Stepped care for back pain: activating approaches for primary care. Ann Intern Med 2001:134:911-7.

32. Maher C, Underwood M, Buchbinder R. Non-specific low back pain. Lancet 2017:389:736-47.

33. Davison GC. Stepped care: doing more with less? J Consult Clin Psychol 2000;68:580-5.

34. Watson JM, Crosby H, Dale VM, et al. AESOPS: a randomised controlled trial of the clinical effectiveness and cost-effectiveness of opportunistic screening and stepped care interventions for older hazardous alcohol users in primary care. Health Technol Assess 2013;17:1-158

35. Zatzick D, Jurkovich G, Rivara FP, et al. A randomized stepped care intervention trial targeting posttraumatic stress disorder for surgically hospitalized injury survivors. Ann Surg 2013;257:390-9.

36. Rogers K, Banis M, Falkenstein MJ, et al. Stepped care in the treatment of trichotillomania. J Consult Clin Psychol 2014;82:361-7.

37. Commissioning stepped care for people with common mental health

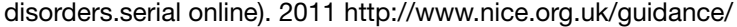
cmg41/resources/non-guidance-commissioning-stepped-care-forpeople-with-common-mental-health-disorders-pdf (Accessed 20 Jan, 2016). 